\title{
Food budget standards and dietary adequacy in low-income families
}

\author{
Michael Nelson*, Katie Dick and Bridget Holmes \\ Department of Nutrition and Dietetics, King's College London, 150 Stamford Street, \\ London SE1 9NN, UK
}

\begin{abstract}
Budget standards are specified baskets of goods and services which, when priced, can represent predefined living standards. 'Low cost but acceptable' (LCA) is a minimum income standard, adequate to provide warmth and shelter, a healthy and palatable diet, social necessities, social integration, avoidance of chronic stress and the maintenance of good health (physical, mental and social) in a context of free access to good-quality health care, good-quality education and social justice. The LCA food budget standard identifies a basket of foods and corresponding menus which provides (for a given household composition) a palatable diet that is consistent with prevailing cultural norms, and that satisfies existing criteria for health in relation to dietary reference values, food-based dietary guidelines and safe levels of alcohol consumption. Two previous studies that explored the relationship between diet and food expenditure in low-income households suggested that the amount spent on food was a good predictor of dietary adequacy, growth and health in children. The current paper will focus on diet and measures of deprivation in 250 low-income households in London. Households were screened for material deprivation (e.g. no car, no fixed line telephone, in receipt of Income Support) using a doorstep questionnaire. Diet was assessed using four $24 \mathrm{~h}$ recalls based on the 'triple pass' method. Expenditure on food and other aspects of household circumstances were assessed by face-to-face interview. Food expenditure in these households was characterized in relation to food budget standards. Further analyses explored the relationships between food expenditure and dietary adequacy, growth in children and measures of deprivation.
\end{abstract}

Food budget standards: Low-income families: Food expenditure: Dietary adequacy

The present paper is presented in two sections. The first deals with food budget standards and their development, including updated estimates for June 2002. The second section is devoted to a preliminary analysis of data from the Low Income Diet Methods Study. Findings on the relationships between energy and nutrient intake in relation to income and spending on food are presented. Discussion focuses on the usefulness of food budget standards for identifying households that may be at risk of food poverty.

The paper addresses three basic questions:

1. is dietary adequacy linked to household income;

2. is dietary adequacy linked to food expenditure;

3. do food budget standards provide a useful cut-off for assessing adequacy of spending on food.

\section{Food budget standards}

Minimum income standards are part of the armoury that Governments and other agencies use to estimate the levels of income and expenditure that represent given standards of living for households within a population. There are three basic approaches (Veit-Wilson, 1998):

1. deprivation indicators;

2. attitudinal judgements;

3. budget standards.

\section{Deprivation indicators}

Deprivation indicators are typically derived from small area population statistics (often from national censuses or nationally-representative samples of the population) on, for example, car ownership, proportion of population unemployed or from ethnic minority groups and housing tenure. Measures are typically collected at the household level, but may represent group summaries of individual behaviours. Examples are the Townsend, Carstairs and Jarman indices. These measures are most useful for identifying areas 
of deprivation or population characteristics most strongly associated with deprivation.

Most European countries carry out household budget surveys (Trichopoulou \& Members of DAFNE II, 1998). These surveys typically review expenditure on all items, including food, clothing, household goods, household services, personal care, leisure, housing costs, fuel, transport, medical costs, costs relating to employment, insurance, pets, alcohol and charitable giving. They provide information on patterns of expenditure for groups of households according to household composition, region, income, age of respondents, level of education, occupation, and area measures of deprivation. They therefore provide the basis for analyses of food expenditure in relation to deprivation and associated measures such as income or education. In some instances household budget surveys provide measures of the quantities of food purchased (e.g. the National Food Survey; Ministry of Agriculture Fisheries and Food, 1996, 1997, 1998, 1999). Estimates of energy and nutrient availability and adequacy can be assessed for groups of households according to socio-economic and deprivation indicators. With suitable manipulation, expenditure data can be used to estimate purchase quantities (Friel et al. 2001) and hence patterns of consumption and adequacy. It is also possible to manipulate household data to estimate average food consumption and energy and nutrient intake by age and gender (Chesher, 1997; Paterakis \& Nelson, 1999), although these manipulations have their limitations.

\section{Attitudinal judgements}

Attitudinal judgements are based on interviews and discussion groups. Respondents are asked to describe the levels of consumption that, in their view, represent a minimum level of adequacy (Gordon \& Pantazis, 1997; Gordon \& Townsend, 2000). They are important in that they represent culturally-appropriate levels of consumption and availability. Their limitation is the lack of objective reference measures associated with dietary adequacy and health.

\section{Budget standards}

Budget standards are specified baskets of goods and services which, when priced, can represent predefined living standards. They are based on a combination of interviews with discussion groups and objective measures of adequacy. For fuel, for example, the amount of gas or electricity that needs to be provided to heat to a given temperature a house with a specified number of rooms and level of insulation can be costed, based on consumption requirements, heating system and prevailing fuel prices. The temperature levels can be reviewed with discussion groups representing different age and household composition groups, taking into account acceptable differences in temperature between living and bedroom areas and seasonal variations.

Budget standards are typically defined at two levels: a 'reasonable' (modest but adequate) standard that represents a standard of living to which most households of modest means would aspire; and a minimum income or level of expenditure below which households could be regarded as being in poverty (low cost but acceptable; LCA). 'Modest but adequate' is defined as an income standard which 'satisfies prevailing standards of what is necessary for health, efficiency, the nurture of children and participation in community activities' (Wynn, 1970) and 'affords full opportunity to participate in contemporary society and the basic options it offers. It is moderate in the sense of lying well above the requirements of survival and decency, and well below levels of luxury as generally understood' (Watts, 1980). LCA is defined as a minimum income standard, adequate to provide warmth and shelter, a healthy and palatable diet, social necessities, social integration, avoidance of chronic stress and the maintenance of good health (physical, mental and social) in a context of free access to good-quality health care, good-quality education and social justice.

The LCA concept is summarized in Fig. 1 (Parker, 1998). Aspects of living that are costed include housing, fuel, personal care, social integration (including holidays and leisure pursuits). These components provide for, or assume freedom from, physical and psychological stresses likely to lead to ill health (e.g. a secure and healthy work environment). The costs relating to these components are assumed to occur in a society in which education, basic health care and social justice are freely available.

The principles behind the LCA food budget calculations are that the baskets of foods should:

1. represent a pattern of consumption that is characteristic of households of a given income level within the UK;

2. contain a balance of foods which will promote shortand long-term health in both adults and children;

3. be based on foods which are widely available at low prices.

The determination of food budget standards is summarized in Fig. 2. There are essentially eight steps to the process:

1. National Food Survey data from 1995 to 1998 provided the starting point for the basket of foods from which the present food budget standards were constructed. Households of a given composition were selected in specified income bands based on an analysis of Family Expenditure Survey data (Office for National Statistics, 1996,

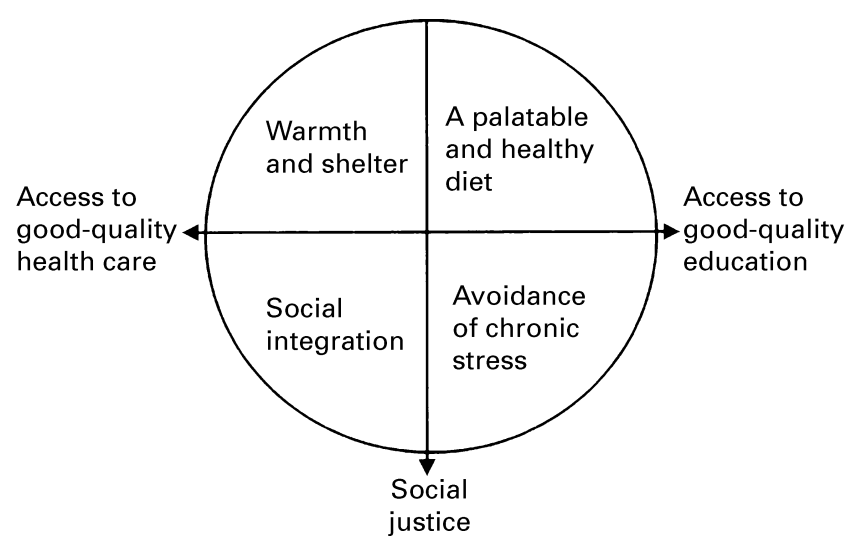

Fig. 1. 'Low cost but acceptable' concept. (From Parker, 1998.) 


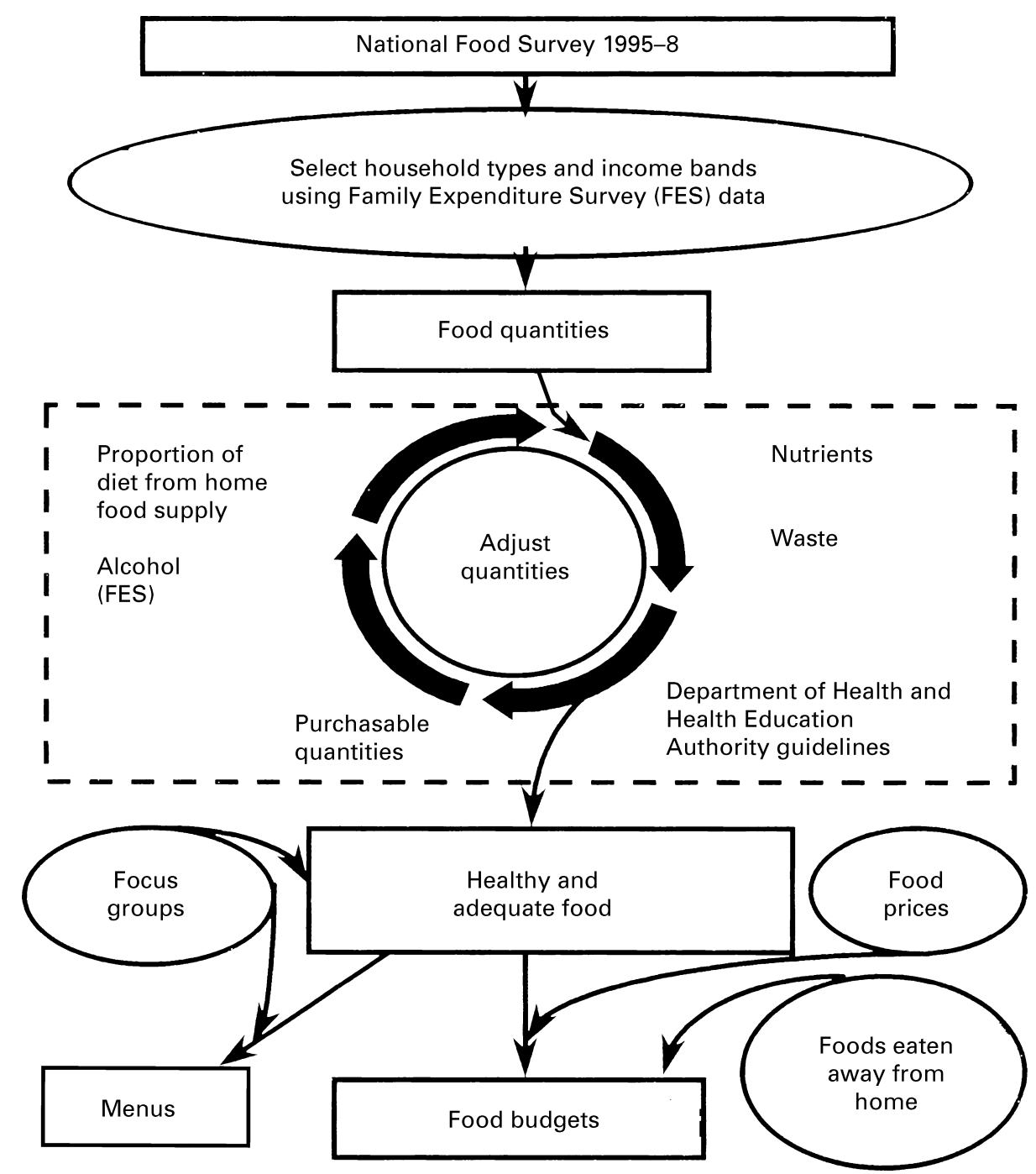

Fig. 2. Development of 'low cost but acceptable' food budget standard. National Food Survey 1995-1998 data was derived from Ministry of Agriculture, Fisheries and Food $(1996,1997,1998,1999)$ and Family Expenditure Survey data was derived from Office for National Statistics (1996, 1997, 1998, 1999).

1997, 1998, 1999). The income bands were those in which, on average, households were spending on food $30 \%$ of their disposable income after housing costs. The $30 \%$ value represents a notional poverty line; any household required to spend $>30 \%$ of their disposable income on food is unlikely to be able to provide the basic necessities for other aspects of living (Orshansky, 1965). In households with two adults and two young children, for example, the LCA income band is represented by households between the 5th and 20th centiles of the income distribution. For a lone mother with two children, the LCA income band is represented by households between the 50th and 75 th centiles. The differences in the choice of income centiles arises from differences in the income distribution between these household types; lone mothers generally have lower incomes than couples with children;
2. the adequacy of the diet was calculated by estimating the nutrient content of the food purchases using the Ministry of Agriculture, Fisheries and Food nutrient conversion factors and comparing the nutrient availability in the household with the total energy and nutrient requirement, based on the dietary reference values (Department of Health, 1991), taking into account waste, consumption of food by visitors and food purchased and eaten away from home;

3. using the minimal possible adjustments, the food purchasing profiles were changed to bring them into line with dietary reference values and Health Education Authority $(1996 a, b)$ guidelines on healthy eating (e.g. five portions of fruit and vegetables daily) and to ensure that estimated nutrient availability was at least $100 \%$ of the reference nutrient intakes, $<35 \%$ energy from total fat (or $33 \%$ when alcohol is included) (Department of Health, 1991); 
4. the total quantity of food purchased was adjusted to provide a diet which provided $100 \%$ of the estimated average requirement (Department of Health, 1991) for energy. The diet was then re-assessed for its overall adequacy. Steps 3 and 4 were repeated until an adequate and healthy food profile was obtained;

5. a food basket was constructed containing items in purchasable quantities (e.g. loaves of bread, tins of fruit) such that the nutrient value was equal to that in step 4. Items identified for pricing were based on focus-group discussions held with eight to ten families of each household type in at least three different locations around the UK;

6. the basket of foods was costed using food prices from two supermarkets (Sainsbury and KwikSave) at January 1998 prices. A component was added for foods purchased away from home based on Family Expenditure Survey data (Office for National Statistics, 1998);

7. last, menus were devised which utilised the items in the food basket, allowing for meals eaten away from home and the presence of visitors;

8. as an additional step, alcoholic beverage consumption was allowed at not more than two-thirds the safe level using Health Education Authority (1996b) guidelines. The safe levels are given as 21 units for men and 14 units for women. Expenditure was costed using prices for alcoholic beverages at Sainsbury and KwikSave. Levels of expenditure based on Family Expenditure Survey data (Office for National Statistics, 1998) for older single females and older couples provided only 6-9 units alcohol per person per week, and these levels of expenditure were retained as the basis for the alcohol component in these budgets. The cost of the food in the basket (and by implication, food quantities) was reduced to allow for the energy content of alcoholic beverages.

Further details of the method can be found in Parker (1999).

Table 1 shows the components of the LCA food budget standards for a couple with two young children (a girl aged 4 years and a boy aged 10 years), a lone mother with two young children (also a girl aged 4 years and a boy aged 10 years), and for older people (65-74 years). The values are based on January 1998 (Parker, 1998) and January 1999 (Parker, 1999) values adjusted to June 2002, allowing for inflation at $3 \%$ /year. Table 2 shows the breakdown of the food budget (with and without an allowance for alcoholic beverage consumption by the adults) for the individual family members in the families with two young children.

The values in Tables 1 and 2 provide the benchmarks against which to assess the relationship between food expenditure on the one hand and dietary adequacy on the other.

\section{The Low Income Diet Methods Study}

The Low Income Diet Methods Study was commissioned and funded by the Food Standards Agency over 22 months between April 2000 and June 2002. The primary aims were to:

Table 1. 'Low cost but acceptable' food budget standards for five household types, inflation adjusted to June 2002 prices*

\begin{tabular}{|c|c|c|c|c|c|}
\hline \multirow[b]{2}{*}{ Budget component } & \multirow{2}{*}{$\begin{array}{l}\text { Two adults, two children } \\
(4 \text { years }+10 \text { years })\end{array}$} & \multirow{2}{*}{$\begin{array}{l}\text { Lone mother, two children } \\
\text { ( } 4 \text { years }+10 \text { years })\end{array}$} & \multicolumn{3}{|c|}{ Older people (65-74 years) } \\
\hline & & & Single woman & Single man & Couple \\
\hline Total food, home budget & $£ 56.11$ & $£ 37.31$ & $£ 22.28$ & $£ 25.51$ & $£ 40.93$ \\
\hline $\begin{array}{l}\text { Foods purchased and eaten away } \\
\text { from home }\end{array}$ & $£ 11.47$ & $£ 5.49$ & $£ 2.73$ & $£ 2.73$ & $£ 5.43$ \\
\hline Total budget: & & & & & \\
\hline $\begin{array}{l}\text { Food only: If no alcohol included } \\
\text { in the diet }\end{array}$ & $£ 67.58$ & $£ 42.80$ & $£ 25.01$ & $£ 28.24$ & $£ 46.37$ \\
\hline $\begin{array}{l}\text { If alcohol included in } \\
\text { the diet }\end{array}$ & $\begin{array}{r}£ 65.47 \\
£ 9.85\end{array}$ & $\begin{array}{r}£ 42.01 \\
£ 4.58\end{array}$ & $\begin{array}{r}£ 24.32 \\
£ 2.46\end{array}$ & $\begin{array}{r}£ 26.66 \\
£ 6.25\end{array}$ & $\begin{array}{r}£ 44.49 \\
£ 8.11\end{array}$ \\
\hline $\begin{array}{l}\text { Alcohol } \\
\text { Food plus alcohol }\end{array}$ & $£ 75.32$ & $£ 46.59$ & $£ 26.78$ & $£ 32.92$ & $£ 52.60$ \\
\hline
\end{tabular}

*Based on January 1998 (Parker, 1998) and January 1999 (Parker, 1999), allowing for inflation at 3\%/year.

Table 2. Costs of a 'low cost but acceptable' food basket according to age and gender in households with two adults and two children or lone-parent households with two children, inflation adjusted to June 2002 prices*

\begin{tabular}{|c|c|c|c|c|}
\hline & \multicolumn{2}{|c|}{ Couple with two children } & \multicolumn{2}{|c|}{ Lone mother with two children } \\
\hline & With alcohol & Without alcohol & With alcohol & Without alcohol \\
\hline Father & $£ 21.94$ & $£ 23.22$ & - & - \\
\hline Mother & $£ 15.43$ & $£ 16.25$ & $£ 14.90$ & $£ 15.68$ \\
\hline Boy 10 years & $£ 16.95$ & $£ 16.95$ & $£ 16.36$ & $£ 16.36$ \\
\hline Girl 4 years & $£ 11.15$ & $£ 11.15$ & $£ 10.76$ & $£ 10.76$ \\
\hline Entire household & $£ 65.47$ & $£ 67.58$ & $£ 42.01$ & $£ 42.80$ \\
\hline
\end{tabular}

*Based on January 1998 (Parker, 1998) and January 1999 (Parker, 1999), allowing for inflation at 3\%/year. 
1. compare the effectiveness and acceptability of three dietary survey methods $(24 \mathrm{~h}$ recall, food checklist, semi-weighed method) $v$. a weighed inventory in low-income households in London. Consumption was measured using each method over $4 \mathrm{~d}$;

2. recommend sampling techniques and dietary methodology for a pilot study for a national survey of diet in low-income households;

3. investigate food consumption, eating patterns and nutrient intakes in low-income households in relation to deprivation indicators.

Households (see Appendix) for the Low Income Diet Methods Study were identified in three stages. First, the sixty most-deprived postal sectors in London were identified using Health Survey for England data relating to aspects of deprivation such as car ownership, receipt of Income Support and overcrowding. Second, addresses were selected within thirteen of the twenty most-deprived postal sectors and five of the remaining forty postal sectors to provide a broad geographical cross-section of deprived areas in London. Last, households were selected on the basis of a doorstep screening interview. The screening interview asked for information relating to indicators of potential deprivation similar to those used in the Health Survey for England (Prior et al. 2002) analysis such as access to a car or van, renting a flat with children, being a lone parent with children $\leq 16$ years of age, living in overcrowded conditions (one or more persons per room), etc. A score of $\geq 3$ qualified the household for inclusion in the study. Where agreement to participate in the main study was obtained, two individuals were selected within the household (except in single-person households), including one child and one adult where possible. The main respondent was asked to complete a questionnaire that included shopping practices and income. Every subject was asked to complete four $4 \mathrm{~d}$ assessments of diet by $24 \mathrm{~h}$ recall, food checklist, semiweighed method and weighed inventory over a period of 10-12 weeks. Respondents were also asked to provide four $24 \mathrm{~h}$ urine collections during the weighed inventory.

Of 2236 households for which contact was made with a responsible adult, 1204 (54\%) completed the screening interview and were assigned a deprivation score. Of these 1204 households, 810 (67\%) had a deprivation score of $\geq 3$ and were deemed eligible for inclusion in the study (see Appendix). Of the 810 households, 494 (61\%) agreed to an appointment to begin the main study and $252(31 \%)$ households completed the study. The analyses in relation to diet presented here are based on 349 respondents in 219 households for whom complete data on diet, income and food expenditure were available. (There were some later exclusions where respondents reported being pregnant or breast feeding, and households with high income who scored three points, for example renting with children, no car, no fixed line telephone.)

Fig. 3 shows the percentage of each of twelve deprivation indicators occurring in the 829 households with at least three deprivation indicators based on doorstep screening (see Appendix). Not surprisingly, in deprived central urban areas few respondents had access to a car or van. Many

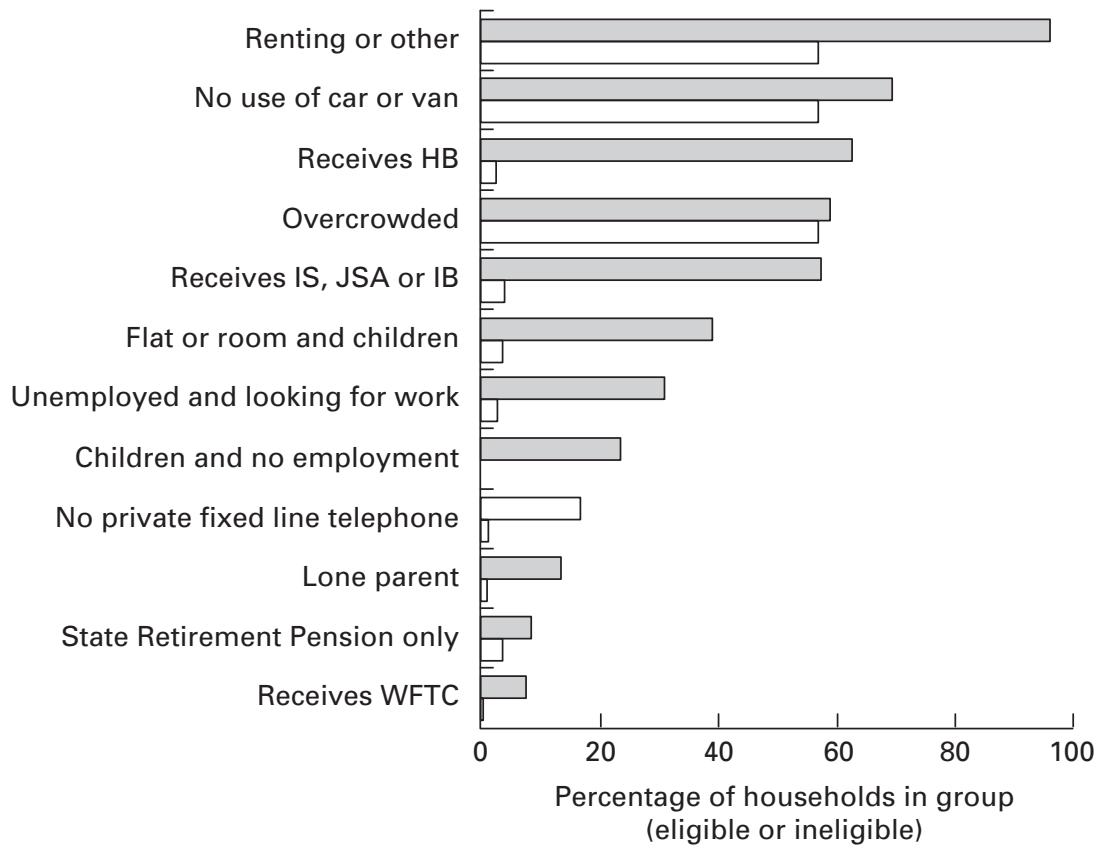

Fig. 3. Percentage of households in the Low Income Diet Methods Study with deprivation characteristic. (खx), Eligible households ( $n$ 829); $(\square)$, ineligible households ( $n$ 375). Renting or other, renting or, for example, living with family and not paying rent; receives HB, in receipt of Housing Benefit; overcrowded, one or more persons per room; IS, Income Support; JSA, Jobseeker's Allowance; IB, Incapacity Benefit; flat or room and children, living in flat or room with children $\leq 16$ years; children and no employment, children $\leq 16$ years and no one employed for $>16 \mathrm{~h}$ /week; lone parent, 1 adult (> 16 years) and one or more children; State Retirement Pension only, no income other than the State Retirement Pension; WFTC, Working Family Tax Credit. For details of study, see pp. 572-573. 
households qualified for Housing Benefit or other benefits such as Income Support. Overcrowding was common. Thirty-five of thirty-eight eligible households with respondents $\geq 60$ years ( $8 \%$ of the eligible sample) subsisted on a state pension as their only source of income.

In order to address the three questions set out at the start of the present paper, Table 3 shows the mean estimated income and estimated food expenditure per person per week, by household group and fourths of the distribution of income within each household group. Table 4 shows similar data relating to fourths of the distribution of food expenditure within each household group. Tables 3 and 4 also show, by way of illustration, intakes of energy and folic acid intake (in absolute terms, and as a percentage of the estimated average requirement and reference nutrient intake respectively; Department of Health, 1991), based on the repeat $24 \mathrm{~h}$ recalls of consumption (a more detailed analysis of these results in relation to various aspects of deprivation has been completed; M Nelson, R Thomas, EA Dowler, K Dick and B Holmes, unpublished results).
Table 3 shows trends in energy intake between income groups within the three household groups, lower-income groups having lower energy and folic acid intakes. As the numbers in each household group were relatively small, none of the trends reached significance. However, when all household types were analysed together in a univariate general linear model, energy intake $(P=0 \cdot 009)$, folic acid intake $(P=0.049)$ and folic acid adequacy as a percentage of the reference nutrient intake $(P=0 \cdot 028)$ were significantly lower in the lowest-income group and higher in the highest-income group.

Table 4 shows patterns of energy and folic acid intake in relation to food expenditure. In the lone parent and adults with children households, energy intakes were higher in the top fourth of the distribution of food expenditure than in the bottom fourth, as were the folic acid intakes in households with adults and children.

Fig. 4 shows the mean spending on food per person per week according to fourths of the distribution of expenditure on food in each of the three households groups. Also shown

Table 3. Mean income (per person per week), expenditure on food (per person per week), and folic acid and energy intakes (per d and as a percentage of reference nutrient intake (RNI) and estimated average requirement (EAR) respectively; Department of Health, 1991)) in 349 subjects in 219 low-income families living in London, according to fourths of income distribution within household-composition groups*

\begin{tabular}{|c|c|c|c|c|c|c|c|c|c|}
\hline & \multicolumn{8}{|c|}{ Fourths of income distribution within household-composition groups } & \multirow{3}{*}{$\begin{array}{c}\text { Statistical } \\
\text { significance o } \\
\text { variation: } P+\end{array}$} \\
\hline & \multicolumn{2}{|c|}{ Bottom fourth } & \multicolumn{2}{|c|}{ Second fourth } & \multicolumn{2}{|c|}{ Third fourth } & \multicolumn{2}{|c|}{ Top fourth } & \\
\hline & Mean & $S E$ & Mean & $S E$ & Mean & $S E$ & Mean & $S E$ & \\
\hline \multicolumn{10}{|l|}{ Adults only } \\
\hline$n$ & \multicolumn{2}{|c|}{28} & \multicolumn{2}{|c|}{25} & \multicolumn{2}{|c|}{27} & \multicolumn{2}{|c|}{25} & \\
\hline $\begin{array}{l}\text { Income (per person per } \\
\text { week) }\end{array}$ & $£ 53.41^{\mathrm{a}}$ & $£ 2.55$ & $£ 97.16^{\mathrm{b}}$ & $£ 2.12$ & $£ 131.14^{c}$ & $£ 2.55$ & $£ 204.16^{d}$ & $£ 6.93$ & 0.000 \\
\hline $\begin{array}{l}\text { Food expenditure (per person } \\
\text { per week) }\end{array}$ & $£ 29.39$ & $£ 2.35$ & $£ 31.58$ & $£ 3.10$ & $£ 31.52$ & $£ 2.48$ & $£ 36.76$ & $£ 3.90$ & 0.353 \\
\hline Energy: $\mathrm{kJ} / \mathrm{d}$ & 7719 & 439 & 8322 & 569 & 8665 & 460 & 8849 & 703 & 0.464 \\
\hline$\%$ EAR & 84 & 6 & 86 & 5 & 86 & 5 & 83 & 6 & 0.968 \\
\hline Folic acid: $\mu \mathrm{g} / \mathrm{d}$ & 205 & 17 & 255 & 35 & 276 & 27 & 299 & 35 & $0 \cdot 127$ \\
\hline$\% \mathrm{RNI}$ & 105 & 8 & 127 & 18 & 138 & 14 & 149 & 18 & $0 \cdot 156$ \\
\hline \multicolumn{10}{|l|}{ Lone parents households } \\
\hline n & \multicolumn{2}{|c|}{22} & \multicolumn{2}{|c|}{23} & \multicolumn{2}{|l|}{22} & \multicolumn{2}{|c|}{23} & \\
\hline $\begin{array}{l}\text { Income (per person per } \\
\text { week) }\end{array}$ & $£ 37.70^{\mathrm{a}}$ & $£ 1.12$ & $£ 51.38^{\mathrm{ab}}$ & $£ 0.68$ & $£ 65.00^{\mathrm{b}}$ & $£ 1.41$ & $£ 119.34^{c}$ & $£ 9.26$ & 0.000 \\
\hline $\begin{array}{l}\text { Food expenditure (per person } \\
\text { per week) }\end{array}$ & $£ 18.12^{\mathrm{a}}$ & $£ 1.07$ & $£ 19.54^{\mathrm{a}}$ & $£ 1.09$ & $£ 21.18^{\mathrm{ab}}$ & $£ 1.16$ & $£ 24.93^{b}$ & $£ 1.30$ & 0.001 \\
\hline Energy: $\mathrm{kJ} / \mathrm{d}$ & $7351^{a}$ & 506 & $7782^{\mathrm{ab}}$ & 448 & $7414^{a}$ & 431 & $9293^{b}$ & 644 & 0.030 \\
\hline$\%$ EAR & 83 & 5 & 86 & 5 & 92 & 5 & 96 & 5 & 0.349 \\
\hline Folic acid: $\mu \mathrm{g} / \mathrm{d}$ & 193 & 24 & 185 & 19 & 194 & 31 & 197 & 15 & 0.983 \\
\hline$\% \mathrm{RNI}$ & 109 & 13 & 106 & 13 & 123 & 17 & 106 & 9 & 0.764 \\
\hline \multicolumn{10}{|l|}{ Adults with children } \\
\hline$n$ & \multicolumn{2}{|c|}{36} & \multicolumn{2}{|c|}{39} & \multicolumn{2}{|c|}{40} & \multicolumn{2}{|l|}{39} & \\
\hline $\begin{array}{l}\text { Income (per person per } \\
\text { week) }\end{array}$ & $£ 18.60^{\mathrm{a}}$ & $£ 1.76$ & $£ 43.85^{\mathrm{b}}$ & $£ 1.04$ & $£ 67.21^{c}$ & $£ 1.68$ & $£ 115.66^{d}$ & $£ 5.31$ & 0.000 \\
\hline $\begin{array}{l}\text { Food expenditure (per person } \\
\text { per week) }\end{array}$ & $£ 15.94^{a}$ & $£ 1.03$ & $£ 20.95^{b}$ & $£ 1.38$ & $£ 17.94^{\mathrm{ab}}$ & $£ 0.93$ & $£ 21.00^{\mathrm{b}}$ & $£ 1.09$ & 0.004 \\
\hline Energy: $\mathrm{kJ} / \mathrm{d}$ & 7305 & 372 & 7150 & 343 & 8447 & 536 & 8205 & 460 & 0.093 \\
\hline$\%$ EAR & $87^{a b}$ & 5 & $83^{b}$ & 4 & $99^{a}$ & 5 & $83^{b}$ & 4 & 0.030 \\
\hline Folic acid: $\mu \mathrm{g} / \mathrm{d}$ & 171 & 16 & 189 & 18 & 209 & 15 & 210 & 16 & 0.302 \\
\hline$\% \mathrm{RNI}$ & 105 & 9 & 116 & 11 & 135 & 9 & 126 & 9 & 0.148 \\
\hline
\end{tabular}

${ }^{a, b, c, d}$ Groups with different superscript letters were significantly different (Tukey's b post-hoc analysis; $P<0.05$ ).

${ }^{*}$ For details of procedures, see pp. 573-574.

†Based on one-way ANOVA of mean daily intakes. 
Table 4. Mean income (per person per week), expenditure on food (per person per week), and folic acid and energy intakes (per $d$ and as a percentage of reference nutrient intake (RNI) and estimated average requirement (EAR) respectively; Department of Health, 1991) in 384 subjects in 240 low-income families living in London, according to fourths of distribution of food expenditure (per person per week) within household composition groups

\begin{tabular}{|c|c|c|c|c|c|c|c|c|c|}
\hline & \multicolumn{8}{|c|}{ Fourths of distribution of food expenditure within household-composition groups } & \multirow{3}{*}{$\begin{array}{c}\text { Statistical } \\
\text { significance } \\
\text { of variation: } P \dagger\end{array}$} \\
\hline & \multicolumn{2}{|c|}{ Bottom fourth } & \multicolumn{2}{|c|}{ Second fourth } & \multicolumn{2}{|c|}{ Third fourth } & \multicolumn{2}{|c|}{ Top fourth } & \\
\hline & Mean & $S E$ & Mean & $S E$ & Mean & SE & Mean & $S E$ & \\
\hline \multicolumn{10}{|l|}{ Adults only } \\
\hline$n$ & \multicolumn{2}{|c|}{28} & \multicolumn{2}{|c|}{34} & \multicolumn{2}{|c|}{26} & \multicolumn{2}{|c|}{17} & \\
\hline $\begin{array}{l}\text { Income (per person } \\
\text { per week) }\end{array}$ & $£ 110.23$ & $£ 13.65$ & $£ 127.92$ & $£ 8.78$ & $£ 113.73$ & $£ 10.61$ & $£ 128.02$ & $£ 13.71$ & 0.578 \\
\hline $\begin{array}{l}\text { Food expenditure (per person } \\
\text { per week) }\end{array}$ & $£ 16.94^{a}$ & $£ 0.60$ & $£ 26.88^{b}$ & $£ 0.52$ & $£ 37.08^{c}$ & $£ 0.64$ & $£ 60.59^{d}$ & $£ 2.35$ & 0.000 \\
\hline Energy: $\mathrm{kJ} / \mathrm{d}$ & 8711 & 498 & 7510 & 427 & 8958 & 498 & 8657 & 879 & $0 \cdot 172$ \\
\hline$\%$ EAR & 93 & 5 & 75 & 4 & 87 & 5 & 85 & 9 & 0.068 \\
\hline Folic acid: $\mu \mathrm{g} / \mathrm{d}$ & 293 & 31 & 242 & 23 & 245 & 22 & 249 & 49 & 0.544 \\
\hline$\% \mathrm{RNI}$ & 148 & 15 & 121 & 12 & 122 & 11 & 124 & 25 & 0.471 \\
\hline \multicolumn{10}{|l|}{ Lone parents } \\
\hline$n$ & \multicolumn{2}{|c|}{23} & \multicolumn{2}{|c|}{30} & \multicolumn{2}{|c|}{21} & \multicolumn{2}{|c|}{16} & \\
\hline $\begin{array}{l}\text { Income (per person per } \\
\text { week) }\end{array}$ & $£ 47.12^{\mathrm{a}}$ & $£ 2.97$ & $£ 76.89^{b}$ & $£ 7.22$ & $£ 64.29^{\mathrm{ab}}$ & $£ 4.84$ & $£ 90.33^{\mathrm{b}}$ & $£ 14.73$ & 0.002 \\
\hline $\begin{array}{l}\text { Food expenditure (per person } \\
\text { per week) }\end{array}$ & $£ 13.76^{\mathrm{a}}$ & $£ 0.49$ & $£ 19.34^{b}$ & $£ 0.18$ & $£ 24.11^{\mathrm{c}}$ & $£ 0.19$ & $£ 30.27^{d}$ & $£ 0.83$ & 0.000 \\
\hline Energy: $\mathrm{kJ} / \mathrm{d}$ & $6979^{a}$ & 410 & $8079^{a b}$ & 435 & $8100^{\mathrm{ab}}$ & 469 & $9037^{b}$ & 883 & 0.089 \\
\hline$\%$ EAR & 78 & 4 & 94 & 5 & 91 & 5 & 94 & 7 & 0.099 \\
\hline Folic acid: $\mu \mathrm{g} / \mathrm{d}$ & 178 & 22 & 211 & 27 & 185 & 15 & 186 & 13 & 0.699 \\
\hline$\% \mathrm{RNI}$ & 104 & 12 & 125 & 15 & 108 & 11 & 99 & 7 & 0.495 \\
\hline \multicolumn{10}{|l|}{ Adults with children } \\
\hline$n$ & \multicolumn{2}{|c|}{37} & \multicolumn{2}{|c|}{39} & \multicolumn{2}{|c|}{38} & \multicolumn{2}{|c|}{40} & \\
\hline $\begin{array}{l}\text { Income (per person per } \\
\text { week) }\end{array}$ & $£ 59.48^{a}$ & $£ 6.08$ & $£ 53.73^{\mathrm{a}}$ & $£ 5.45$ & $£ 54.51^{\mathrm{a}}$ & $£ 5.16$ & $£ 80.27^{b}$ & $£ 7.87$ & 0.008 \\
\hline $\begin{array}{l}\text { Food expenditure (per person } \\
\text { per week) }\end{array}$ & $£ 10.82^{\mathrm{a}}$ & $£ 0.48$ & $£ 15.93^{b}$ & $£ 0.16$ & $£ 20.53^{c}$ & $£ 0.21$ & $£ 28.14^{d}$ & $£ 0.92$ & 0.000 \\
\hline Energy: $\mathrm{kJ} / \mathrm{d}$ & 7351 & 381 & 7841 & 431 & 7519 & 423 & 8410 & 515 & 0.343 \\
\hline$\%$ EAR & 91 & 4 & 93 & 5 & 84 & 5 & 85 & 4 & 0.353 \\
\hline Folic acid: $\mu \mathrm{g} / \mathrm{d}$ & $173^{a}$ & 10 & $190^{\mathrm{ab}}$ & 14 & $181^{a b}$ & 16 & $235^{b}$ & 22 & 0.029 \\
\hline$\% \mathrm{RNI}$ & 115 & 7 & 122 & 9 & 105 & 9 & 139 & 12 & 0.085 \\
\hline
\end{tabular}

†Based on one-way ANOVA of mean daily intakes.

a,b,c,d Groups with different superscript letters were significantly different (Tukey's b post-hoc analysis; $P<0.05$ ).

${ }^{*}$ For details of procedures, see p. 574.

are estimates of the LCA food budget standard allowing for variations in household composition (LCA per person per week is $£ 22.10$ for adults only, $£ 15.73$ for lone parents and $£ 16.58$ for adults with children at June 2002 prices). Between one-third and one-half of households reported spending less than the LCA level on food.

\section{Discussion}

Food budget standards are intended to help identify a level of spending on food below which it is likely that households are at increased risk of nutritional inadequacy. The present paper provides an introduction to the methodology for the development of food budget standards and a preliminary analysis of the relationship between reported spending on food and dietary intake in some recently-collected data from low-income households in London.

The underlying principles embodied in the LCA concept and the method of determination of the food budget standards are illustrated in Figs. 1 and 2. The LCA food budget standards presented here have been uprated from January 1998 and 1999 food prices, allowing for $3 \%$ inflation per year. They may, therefore, not correspond exactly to the costs of an LCA food basket based on direct computation using current food prices. For the purposes of this exercise, however, they probably provide a reasonable guideline for the LCA level of expenditure against which the adequacy of reported diets might be assessed.

The LCA budgets shown in Table 1 allow for food eaten away from home (as assessed by spending in the Family Expenditure Survey for low-income households of the appropriate household composition) and the inclusion of alcohol for the adults. The budgets should be regarded as indicative rather than prescriptive, i.e. they represent levels of spending on all aspects of provision of food and drink that are likely to be appropriate for families at the LCA level of income and expenditure. It is presumed that within a budget of this amount families would be able to purchase food and 


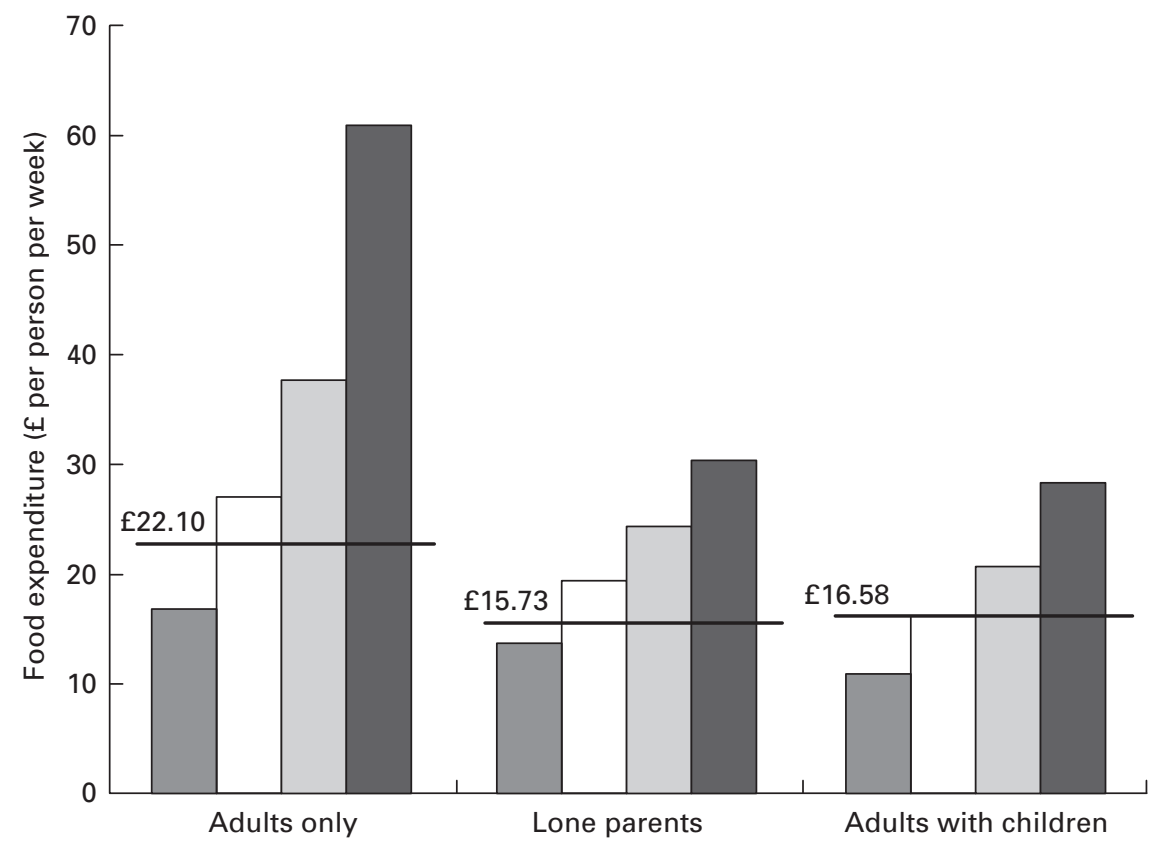

Fig. 4. Mean expenditure on food (per person per week) by fourths of the distribution of expenditure in each of three household groups in the Low Income Diet Methods Study, and 'low cost but acceptable' expenditure. ( fourth; —, 'low cost but acceptable' food budget standard (for details, see pp. 570-571). For details of study, see pp. 572-573.

drink that would satisfy their requirements nutritionally, culturally and socially, and that between households there would be considerable variation in the actual foodstuffs purchased.

Variations in food budgets between household types reflect variations in the nutritional requirements of household members (i.e. men have higher requirements for energy and many nutrients compared with women) and economies of scale (i.e. the sum of the expenditure for single males and single females aged $65-74$ years is greater than the LCA food budget for a couple within the same ageband). Spending on alcohol appears to be substantially lower for the older adults compared with the younger adults, as this finding reflects the levels of drinking reported in the Family Expenditure Survey, which is less than the twothirds of the safe level of consumption adopted for the LCA budgets for the younger adults. In Table 2 variations in the estimated LCA budget for individuals of given age and gender groups is due to variations in the starting points for the LCA food baskets based on the National Food Survey data.

The findings in Table 3 suggest that income is an important predictor of dietary adequacy. Lower income levels are generally associated with lower levels of energy intake in all three household types, although this finding might be partly accounted for by differential underreporting in the lowest income groups, as well as differences in age, gender and ethnic group distributions. Folic acid intakes expressed as a percentage of the reference nutrient intake are $25-50 \%$ lower in the lowest income group in the households with adults only or adults with children. There was no obvious trend with income in folic acid intakes in the lone-parent households. This finding may represent the greater success that lone parents have in providing higher levels of fruits and vegetables compared with other household types. Further planned analysis of intake data relating to other nutrients and specific foodstuffs will help to clarify this issue.

The levels of food expenditure by fourths of the distribution in each household group are shown graphically in Fig. 4, together with the inflation-adjusted LCA food budget standards. The interview question regarding the amount spent on food is very basic (see Appendix). The response is based on a single best estimate of expenditure on food and drink; it is not based on a record of expenditure (as in the Family Expenditure Survey and the National Food Survey). It was assumed that most families on low income apply some form of budgeting to their weekly expenditure, and that they would, therefore, be able to provide a reasonable estimate of their weekly food and drink budget. The similarity between the reported levels of expenditure on food in these households and the LCA level shows that there is consistency between the two independently-derived sets of data (LCA levels and food expenditure). This consistency reflects a reasonable amount of internal validity at the group level. It is not possible to comment on the validity of the food expenditure estimates at the household level.

Reported differences in energy and folic acid intake between the food-expenditure groups (Table 4) were generally smaller than between the income groups (Table 3 ). There is no obvious difference in the variability of intake (based on standard errors of the mean) between the two sets of findings. In this preliminary analysis income appears to be a better predictor of dietary adequacy than level of expenditure on food. Previous studies exploring the relationships between spending on food and, for example, growth in 
children (Nelson \& Naismith, 1979; Nelson, 2000) suggest that spending on food is an important predictor of growth and health in children from low-income families. Further explorations of spending on food in relation to a more comprehensive set of measures of food consumption and nutrient intake and other aspects of diet-related health will be reported in future papers.

\section{Appendix}

\section{The Low Income Diet Methods Study}

Project Directors: Michael Nelson (King's College London), Roger Thomas (National Centre for Social Research), Elizabeth Dowler (University of Warwick). Nutrition researchers: Katie Dick and Bridget Holmes. Interviewers: Rosa Bonini, Sian Burr, Angela Costetsos, Edith Matovu, Paul McGee, Martina Philips and Caireen Roberts. Administration and coding: Jo Francis and Oliver Redfern.

Definition of 'household'. Technically, the unit of selection was not the household but the catering unit (groups of people who shop, prepare food and eat together). It was possible to have more than one catering unit per household. In practice, almost all households were individual catering units. For the sake of simplicity, the unit of selection referred to throughout the present paper is the 'household'.

Screening procedure. Interviewers tallied the deprivation score on the doorstep in order to identify households who were asked to take part in the main study. When the screening data were entered on computer and the score computed automatically, twenty-two households were identified who had a score of 3 or more and should have been invited to participate in the main study but were incorrectly excluded by the interviewer (false negatives) and three that had a score of 2 but who were invited to take part (false positives). The net difference of nineteen households (829 v. 810) is reflected in the data analysed for Fig. 3.

Interview question about the amount of money spent on food. 'I know you haven't kept a spending record, but could you tell me how much your household (catering unit) usually spends on food and drink each week? I'd like you to include food and drink (including alcoholic drinks) and food and drink purchased away from home. Include top-up shopping, school dinners, and money given to children for food purchases. I don't want you to include other items such as cleaning materials, cigarettes, pet food, newspapers or magazines.'

\section{References}

Chesher A (1997) Diet revealed?: Semi-parametric estimation of nutrient intake age relationships. Journal of the Royal Statistical Society 160A, 389-420.

Department of Health (1991) Dietary Reference Values for Food Energy and Nutrients for the United Kingdom. Report on
Health and Social Subjects no. 41. London: H.M. Stationery Office.

Friel S, Nelson M, McCormack K, Kelleher C \& Thriskos P (2001) Methodological issues using household budget survey expenditure data for individual food availability estimation: Irish experience in the DAFNE pan-European project. Public Health Nutrition 4, 1143-1148.

Gordon D \& Pantazis C (editors) (1997) Breadline Britain in the 1990's. Aldershot, Hants: Ashgate.

Gordon D \& Townsend P (editors) (2000) Breadline Europe. Bristol: Policy Press.

Health Education Authority (1996a) Enjoy Healthy Eating. London: HEA.

Health Education Authority (1996b) Think About Drink. London: HEA.

Ministry of Agriculture, Fisheries and Food (1996) Household Food Consumption and Expenditure, 1995. London: H.M. Stationery Office.

Ministry of Agriculture, Fisheries and Food (1997) Household Food Consumption and Expenditure, 1996. London: H.M. Stationery Office.

Ministry of Agriculture, Fisheries and Food (1998) Household Food Consumption and Expenditure, 1997. London: The Stationery Office.

Ministry of Agriculture, Fisheries and Food (1999) Household Food Consumption and Expenditure, 1998. London: The Stationery Office.

Nelson M (2000) Childhood nutrition and poverty. Proceedings of the Nutrition Society 59, 307-315.

Nelson M \& Naismith DJ (1979) The nutritional status of poor children living in London. Journal of Human Nutrition 33 , 33-45.

Office For National Statistics (1996) Family Spending 1995. London: H.M. Stationery Office.

Office For National Statistics (1997) Family Spending 1996. London: H.M. Stationery Office.

Office For National Statistics (1998) Family Spending 1997. London: The Stationery Office.

Office For National Statistics (1999) Family Spending 1998. London: The Stationery Office.

Orshansky M (1965) Counting the poor. Another look at the poverty profile. Social Security Bulletin 28, 3-29.

Parker H (editor) (1998) Low Cost but Acceptable: A Minimum Income Standard for Families with Children in the UK. Bristol: Policy Press.

Parker H (editor) (1999) Low Cost but Acceptable Incomes for Older People. Bristol: Policy Press.

Paterakis S \& Nelson M (1999) Household food survey and individual nutrition survey estimates of food availability in selected households. Scandinavian Journal of Nutrition 34, Suppl., 88S.

Prior G, Teers R, Brookes M \& Primatesta P (2002) Health Survey for England 2000. Methodology and Documentation. London: The Stationery Office.

Trichopoulou A and members of DAFNE II (1998) Network for the Pan-European Food Data Bank based on Household Budget Surveys. Brussels: European Commission.

Veit-Wilson J (1998) Setting Adequacy Standards. Bristol: Policy Press.

Watts H (1980) New American Family Budget Standards: Report by the Expert Committee on Family Budget Revisions. Madison, WI: University of Wisconsin.

Wynn M (1970) Family Policy. London: Michael Joseph. 